\title{
Acute effects of trichloroethylene on blood concentrations and performance decrements in rats and their relevance to humans
}

\author{
R Kishi, I Harabuchi, T Ikeda, Y Katakura, H Miyake
}

\begin{abstract}
This study was designed to clarify the nature of effects of trichloroethylene (TCE) on the central nervous system, and to determine the critical concentrations in blood associated with specific behavioural changes. This was achieved by a follow up of the whole time course of TCE intoxication during and after exposure. The effects of a single four hour exposure to TCE on signalled bar press shock avoidance in rats were tested by methods previously applied to investigate the acute neurobehavioural effects of exposure to toluene. The effects of TCE on the central nervous system were different from those of toluene. Even low exposure to TCE induced shock avoidance performance decrements in rats. Rats exposed to $250 \mathrm{ppm}$ TCE showed a significant decrease both in the total number of lever presses and in avoidance responses at 140 minutes of exposure compared with controls. The rats did not recover their preexposure performance until 140 minutes after the exhaustion of TCE vapour. Exposures in the range $250 \mathrm{ppm}$ to $2000 \mathrm{ppm}$ TCE for four hours produced concentration related decreases in the avoidance response rate. No apparent acceleration of the reaction time was seen during exposure to 1000 or 2000 ppm TCE. The latency to a light signal was somewhat prolonged during the exposure to 2000 to $4000 \mathrm{ppm}$ TCE. It is estimated that there was depression of the central nervous system with slight performance decrements and the corresponding blood concentration was 40 $\mu \mathrm{g} / \mathrm{ml}$ during exposure. Depression of the central nervous system with anaesthetic performance decrements was produced by a blood TCE concentration of about $100 \mu \mathrm{g} / \mathrm{ml}$. These results showed effects of TCE on the central nervous system that were considered to be a function of both the exposure concen-
\end{abstract}

Department of Public Health, Sapporo Medical College, Sapporo 060 Japan

R Kishi, I Harabuchi, T Ikeda, Y Katakura, H Miyake tration and the duration of exposure, which are closely related to the TCE concentration in blood.

(British Fournal of Industrial Medicine 1993;50:470-480)

Trichloroethylene (TCE) has long had application as a degreasing agent and solvent in industry. Evidence that TCE might be a carcinogen has reduced its use during recent decades, but it is still widely used because of its powerful degreasing action. It has also been used clinically as a surgical anaesthetic and analgesic. ${ }^{1}$

It is highly lipid soluble and readily distributes in the central nervous system. Symptoms of the central nervous system such as headache, dizziness, drowsiness, fatigue. ${ }^{2-4}$ abnormal electroencephalogram, ${ }^{56}$ and deficits in psychomotor performance ${ }^{7-9}$ have been reported in workers exposed to TCE. Various experimental models have been used in the study of the disorder of neurobehavioural function caused by the exposure to TCE. ${ }^{10-14}$ From the available information, however, it is difficult to decide such basic issues as what the extent or threshold of the effects is, and how are acute neurobehavioural effects of TCE different from those of other organic solvents. Also, there is little evidence available regarding the whole time course of TCE intoxication during and after exposure. With experimental exposures to organic solvents it is especially important to measure solvent concentrations to assess possible threshold or saturation effects or other dose related non-linearities. ${ }^{15}$

From this viewpoint, we investigated the neurobehavioural effects of a single exposure to TCE in rats by the performance of conditional avoidance response, which was the same method applied to test acute toluene neurotoxicity. ${ }^{15} \mathrm{We}$ also estimated the critical blood TCE concentrations, which is believed to be related to the performance disorder.

\section{Methods}

ANIMALS AND APPARATUS

We used male Wistar rats seven weeks of age. All experiments were performed under a dark-light 


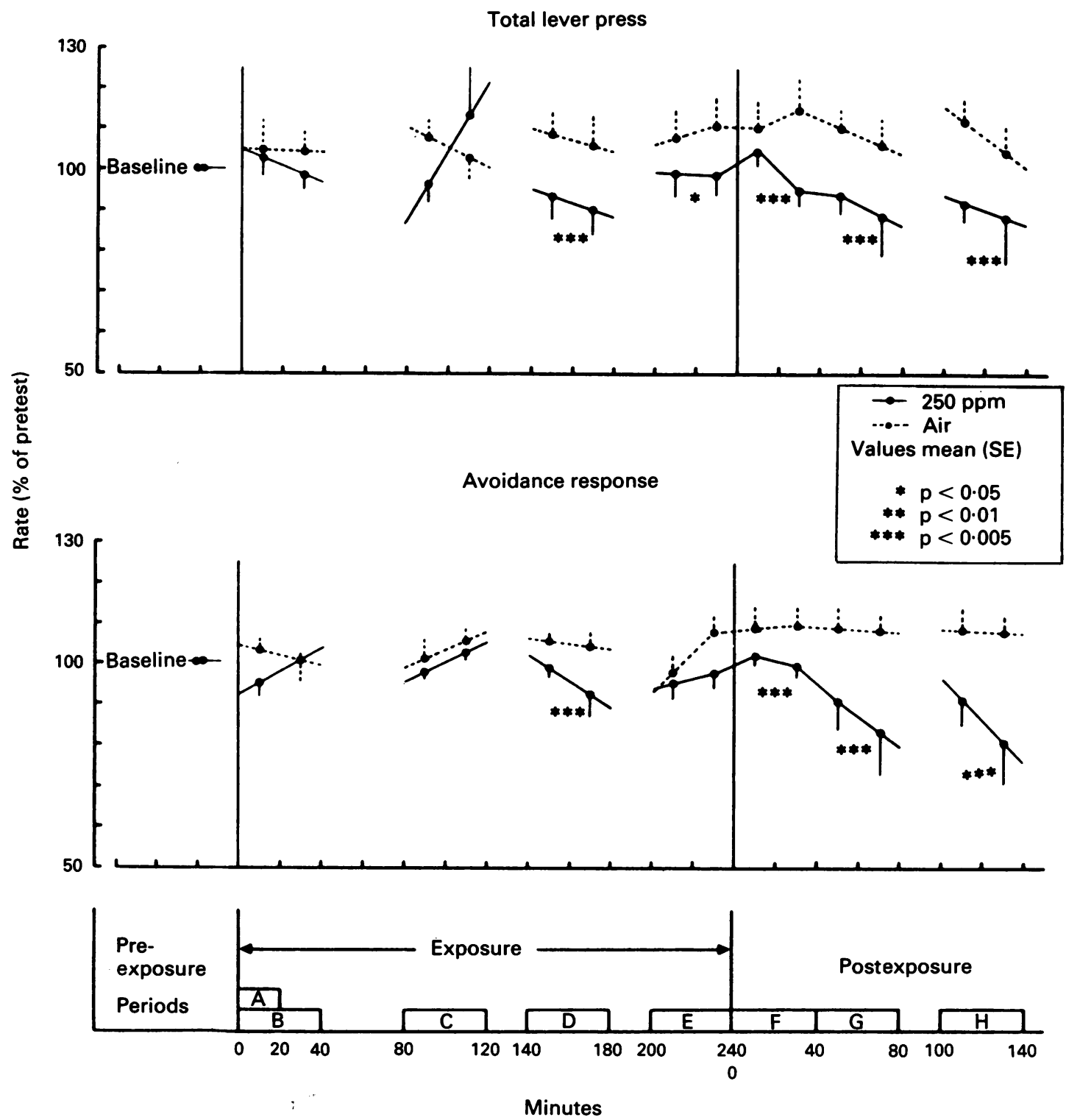

Figure 1 Performance changes of rats during and after a four hour inhalation exposure to 250 ppm TCE.

cycle consisting of alternating 12 hour periods, with the dark period beginning at 700 am. The apparatus used in the behavioural test consisted of Skinner boxes placed in a gas chamber and programming and recording equipment. A shock generator and scrambler (BRS/LVE) was used to deliver a $2.5 \mathrm{~mA} \mathrm{DC}$ shock to the grid floor of each Skinner box for $0.2 \mathrm{~s}$. The experimental contingencies were controlled by a Sord M23 microcomputer and related peripherals.
EXPOSURE

Static exposure was carried out in two similar stainless steel gas chambers $(70 \times 70 \times 120 \mathrm{~cm}) .^{16}$ Two chambers were simultaneously exposed, with the calculated volume of TCE introduced from an upper inlet by a vaporiser. Rats were exposed to various concentrations of TCE (250, 500, 1000, 2000 , and $4000 \mathrm{ppm}$ in ascending order) and to air under identical conditions in each exposure. The concentration of TCE vapour was determined with 


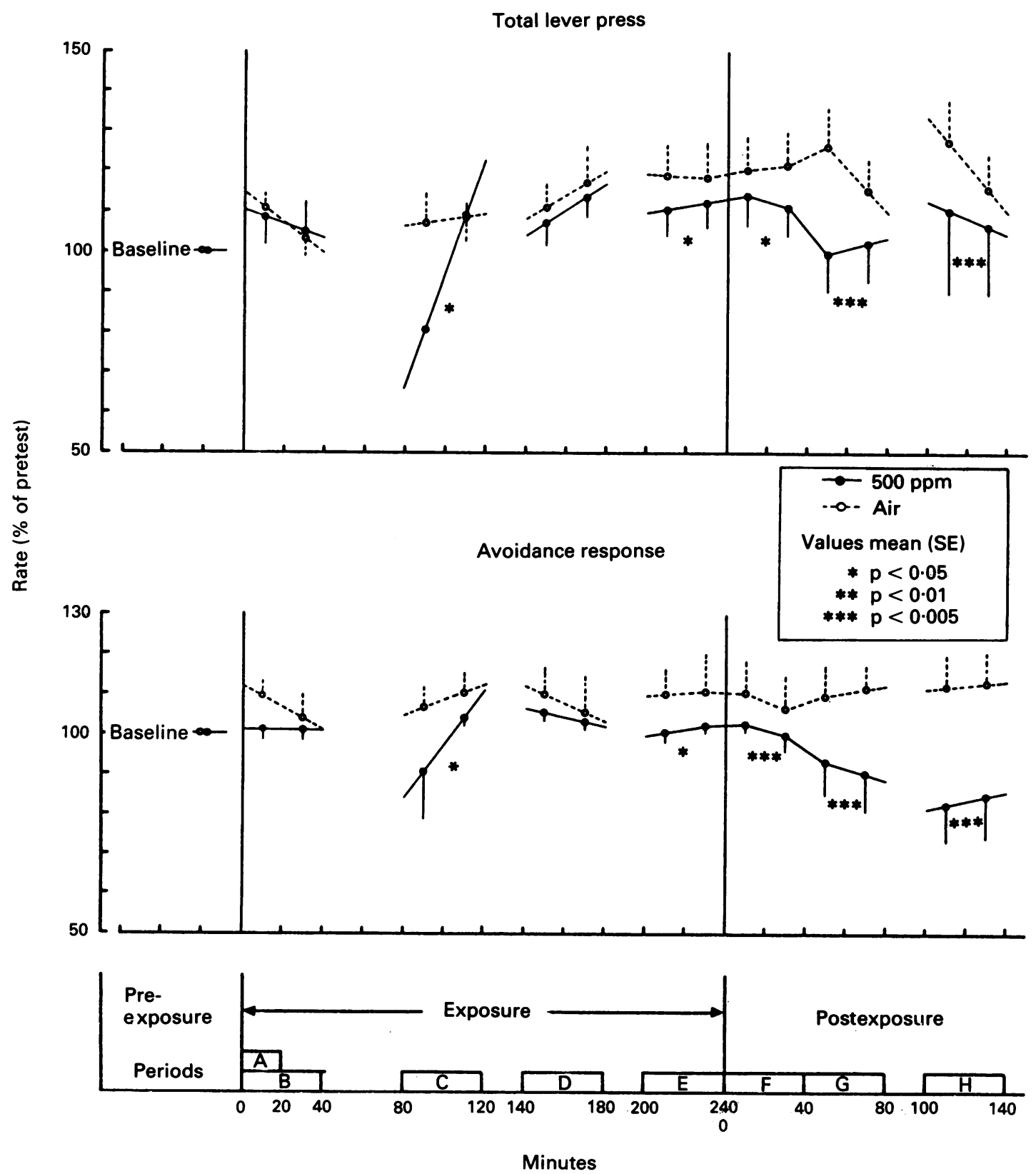

Figure 2 Performance changes of rats during and after a four hour inhalation exposure to 500 ppm TCE.

a Shimazu 4 BPTF gas chromatograph.

\section{BEHAVIOURAL PROCEDURES}

The shock avoidance response (fixed negative interval schedule with a light signal) ${ }^{17}$ was used to establish the behavioural baseline for the observation changes after exposure to TCE. The animals were trained for one hour every two days with a reinforcement schedule having a 10 second shock to shock interval and a light signal was presented for five seconds before every electric shock. Under this schedule, the animals were able to avoid an electric shock if they pressed the lever when the light signal was on. 
Total lever press

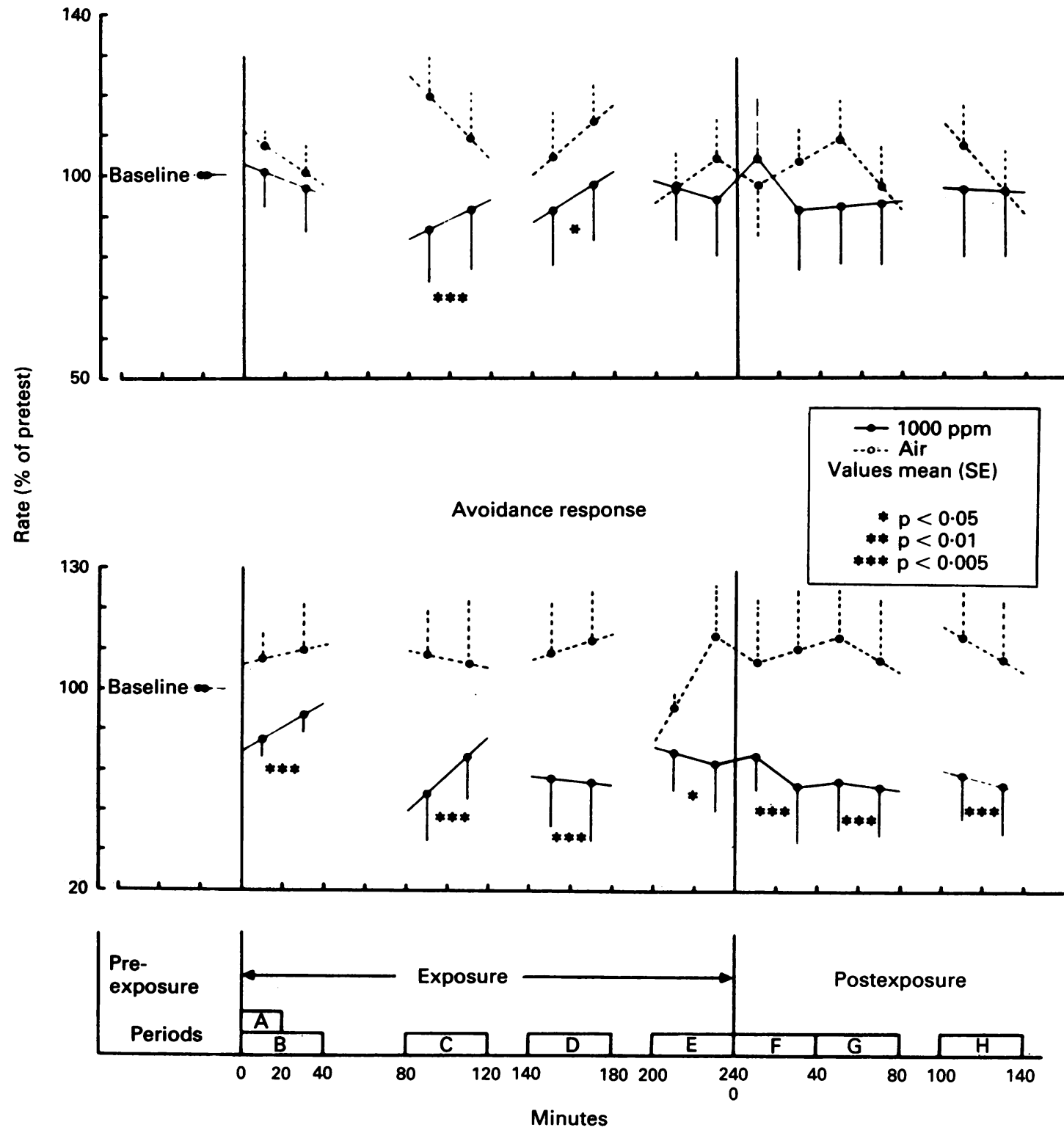

Figure 3 Performance changes of rats during and after a four hour inhalation exposure to 1000 ppm TCE.

The behavioural baseline was established in the animals after 10 to 15 training sessions. After this, eight rats in which avoidance rate succeeded in over $80 \%$ of the trials were selected and exposed first to air as a control and then to TCE and air alternatively. The animals were placed into Skinner boxes to test their lever pressing behaviour under the described avoidance schedule from 900 am every day. They were exposed to TCE or air for four hours from 1000 am to $200 \mathrm{pm}$ and the observations were continued for about two hours after the exhaustion of TCE. The interval between exposure to TCE in any rat was set at 10-20 days to avoid lingering effects of the previous exposure. The numbers of lever presses and shocks received per 20 minute period during these seven hour test periods were adopted as the behavioural test variables. 


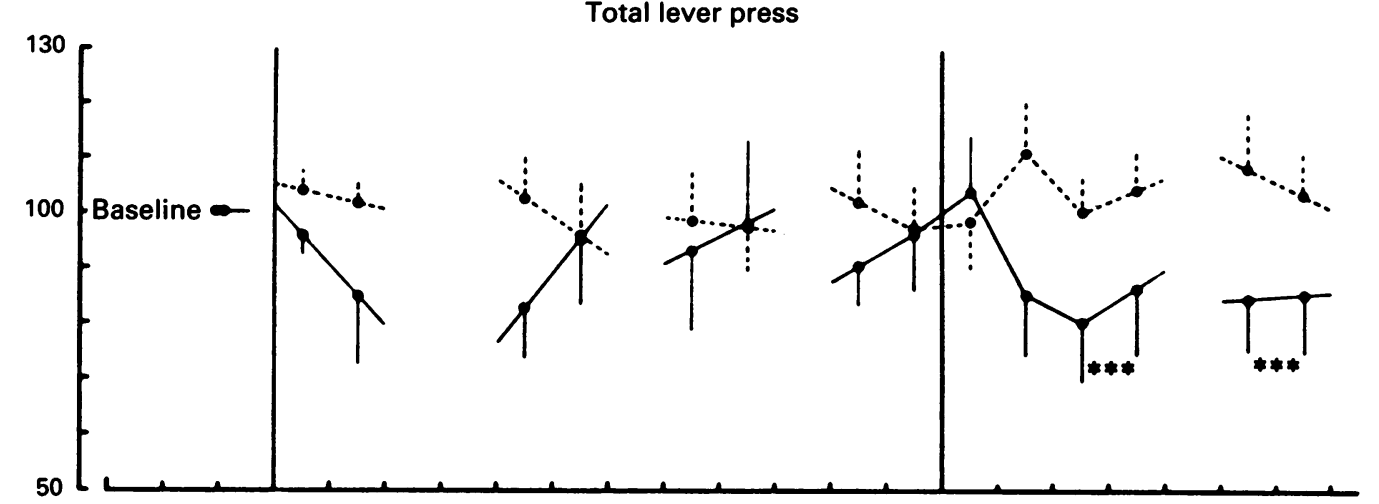

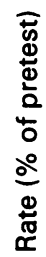

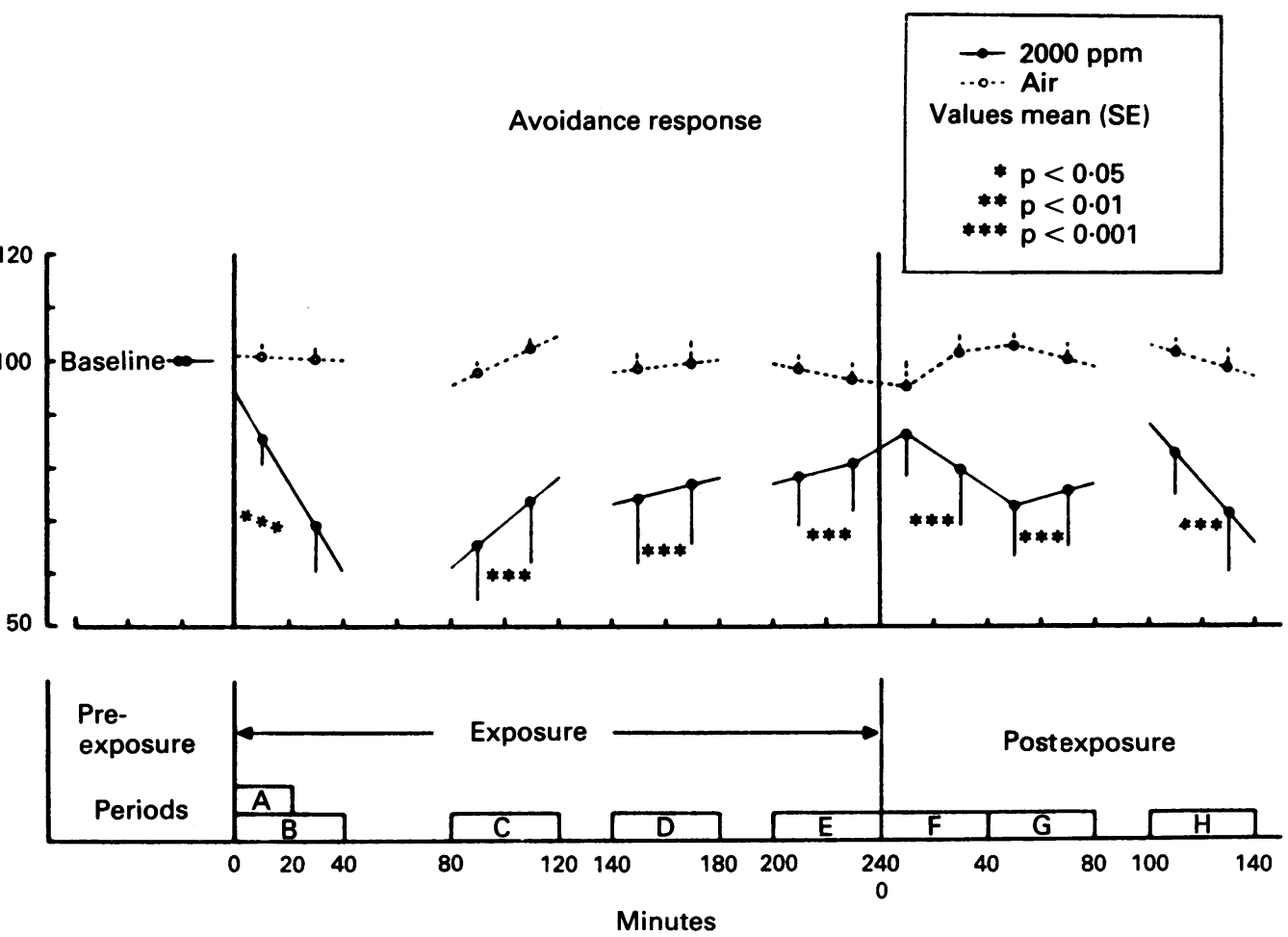

Figure 4 Performance changes of rats during and after a four hour inhalation exposure to 2000 ppm TCE.

SOLVENT ANALYSIS

To measure the concentrations of TCE in blood during and after exposure, 140 male Wistar rats equivalent in weight to the animals of the behavioural experiment were used. They were exposed to TCE for four hours at the same concentrations as those in the behavioural experiments $(250,500,1000,2000$, and $4000 \mathrm{ppm})$. The rats were decapitated and blood was dispensed into all glass containers with heparin. The concentration of TCE in blood was determined by a modified gas chromatographic equilibration method. ${ }^{18}$

STATISTICAL ANALYSIS

Effects of TCE were evaluated by comparing the performance of rats during and after exposure with their own performance in air. Statistical significance was determined by three way analysis of variance in 


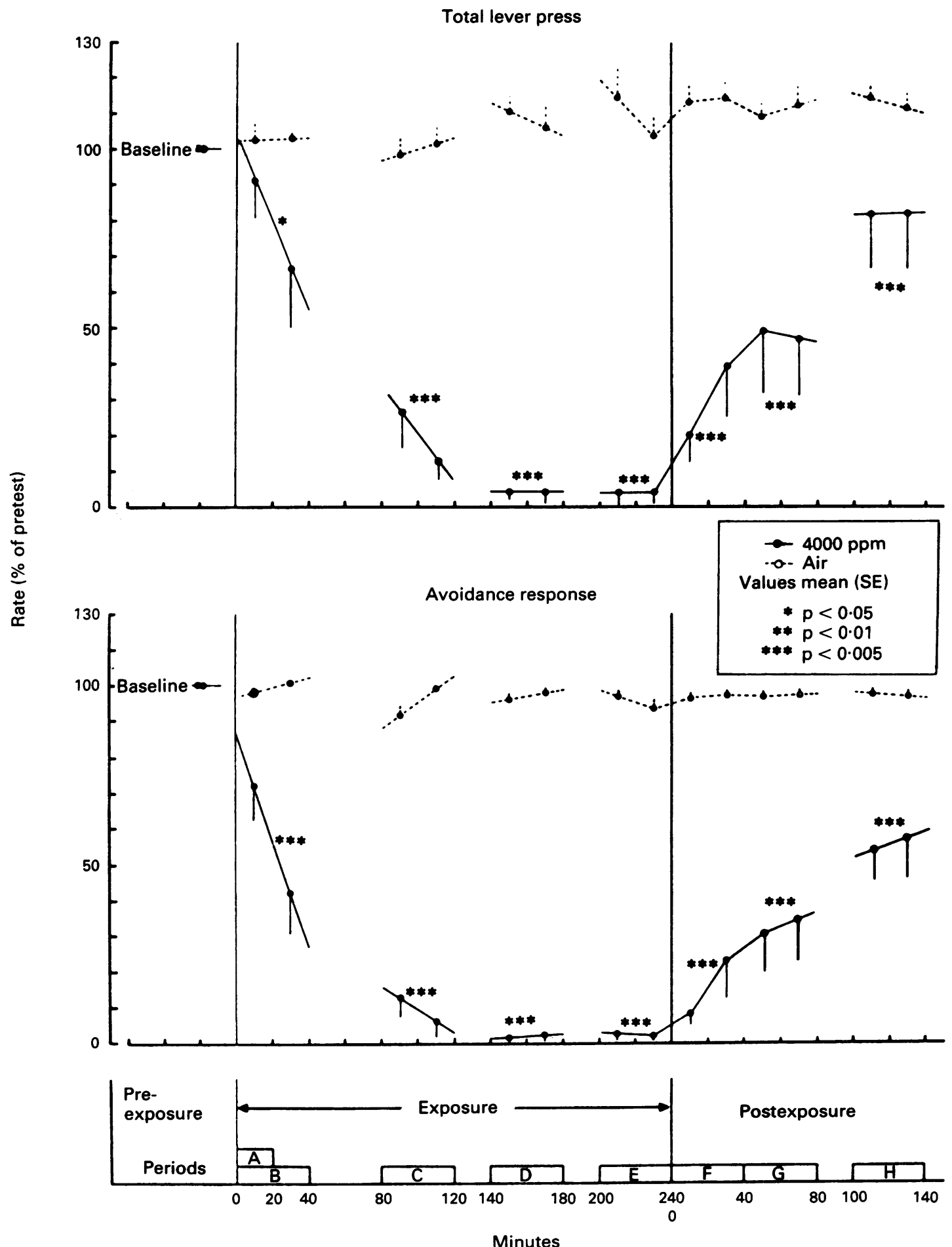

Figure 5 Performance changes of rats during and after a four hour inhalation exposure to 4000 ppm TCE. 
which the exposure effects, time effects, and the differences within eight individual rats were included as the three factors.

\section{Results}

Rats exposed to $250 \mathrm{ppm}$ TCE showed a significant decline in both the total number of lever presses and in avoidance responses at 140 minutes of exposure compared with the controls. The rats did not recover to the level of performance before the exposure until 140 minutes after the exhaustion of TCE vapour (fig 1).

The $500 \mathrm{ppm}$ dose of TCE induced a significant decrease in total lever presses at 120 minutes of exposure compared with the matched air controls. The avoidance response rate was significantly lower than that of controls at periods before and after 240 minutes of exposure (fig 2).

Rats exposed to $1000 \mathrm{ppm}$ TCE for at least 20 minutes produced a statistically significant decrease in the avoidance response rate. Performance decrements continued during all periods of four hour exposure and even until 140 minutes after the removal of TCE vapour (fig 3).

The avoidance response rate decreased more after exposure to $2000 \mathrm{ppm}$ TCE, to about $40 \%$ compared with the pretest performance. Under these circumstances, however, the mean number of total lever presses did not change greatly during exposure periods. This was mainly because of large variability among the animals when they were exposed to $1000 \mathrm{ppm}$ and $2000 \mathrm{ppm}$ TCE. Two out of eight rats showed anaesthetic performance decrements when exposed to 1000 and $2000 \mathrm{ppm}$ TCE, whereas two other rats showed responses somewhat higher than the baseline level under the same exposure conditions (fig 4).

Both the number of lever presses and the avoidance response rate decreased drastically after exposure to $4000 \mathrm{ppm}$ TCE. Anaesthetic performance disorders such as ataxia or no response to either light or electric shock were found in all exposed rats. After stopping exposure, one rat died, and seven of the eight rats showed a gradual recovery of performance (fig 5 ).

Figure 6 summarises the dose-response relation of the number of avoidance responses under the different concentrations of TCE. The number of avoidance responses decreased under all of the concentrations studied. Exposure to 250 to $2000 \mathrm{ppm}$ TCE produced a concentration related decrease in the avoidance response, whereas $4000 \mathrm{ppm}$ TCE had rather different features. Avoidance performance under $4000 \mathrm{ppm}$ TCE was closely related to

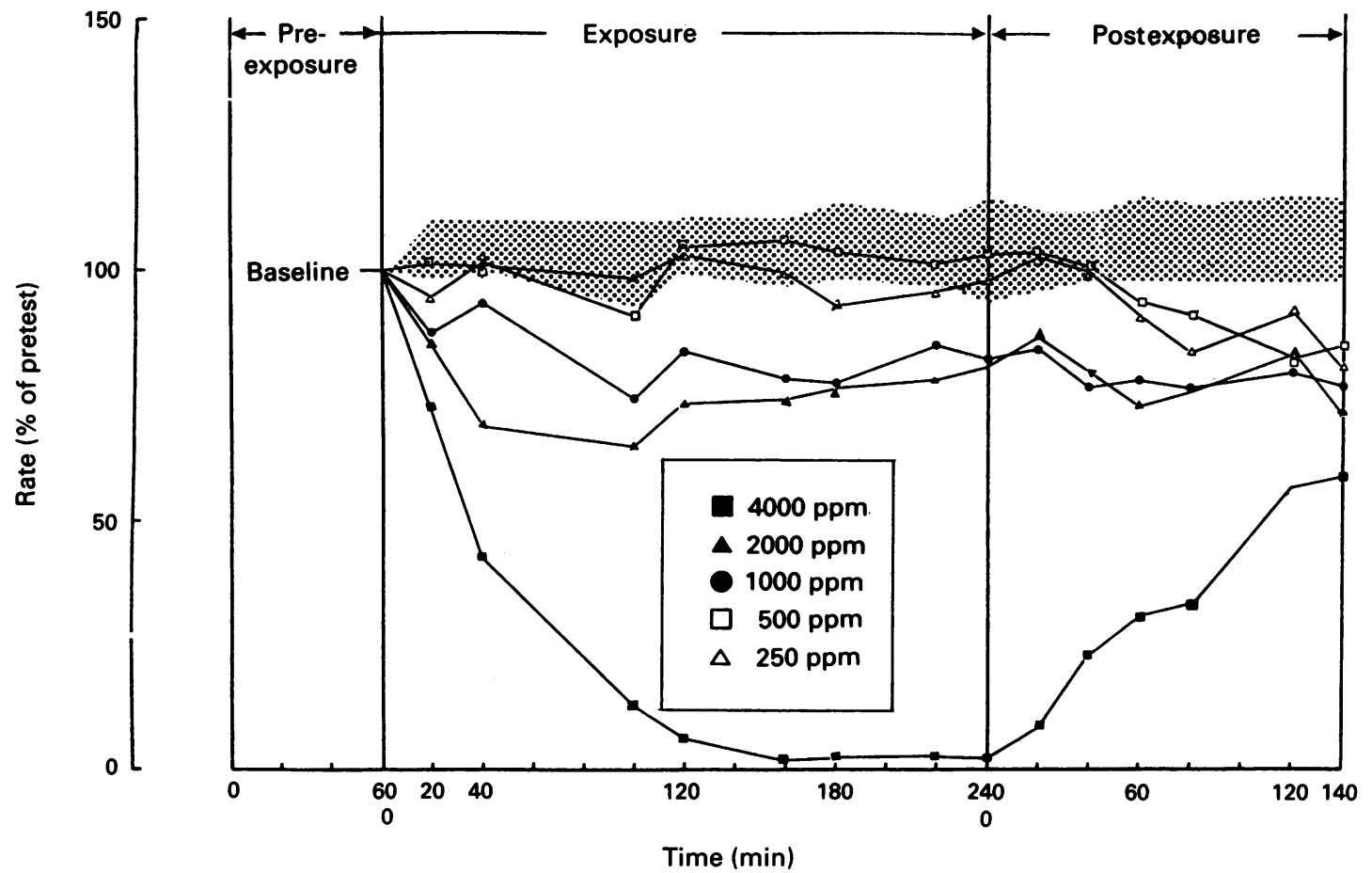

Figure 6 Dose-response relation of TCE exposure to the avoidance responses. Each point indicates the mean of the avoidance responses expressed as a percentage of the pretest of eight rats during seven hour test periods under each TCE concentration. The dotted shadows show the range of the control exposure (air), which includes the maximum and minimum points. 


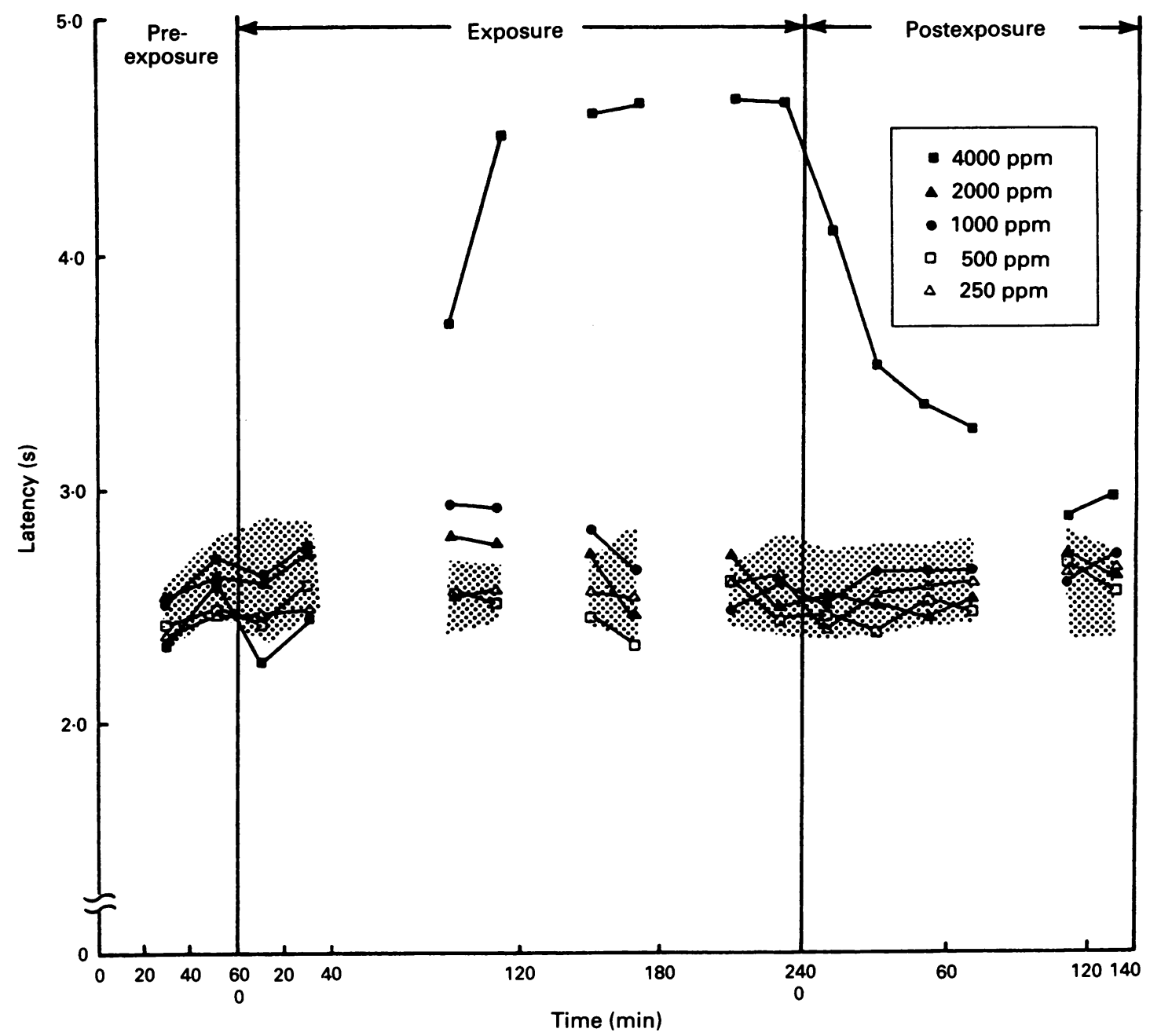

Figure 7 Dose-response relation of TCE exposure to latency. Each point indicates the mean of the time elapsed from the start of a light signal to the lever press response. The dotted shadows show the mean (SD) of the control exposure (air).

the time during and after exposure to TCE.

Figure 7 shows the latency, that is, the time elapsed from when the light was delivered as a signal in the conditioned avoidance response until the time when the rat pressed the lever. The latency to the light signal was prolonged during the exposure to 1000 to $2000 \mathrm{ppm}$ TCE. Acceleration of the reaction time was only seen before the anaesthetic phase at the beginning of exposure to $4000 \mathrm{ppm}$.

Figure 8 shows TCE uptake (inhalation) and elimination in the blood of rats exposed to TCE concentrations of from 250 to $4000 \mathrm{ppm}$ for four hours. As a whole, there was a progressive increase in the quantity of TCE in blood throughout the four hour inhalation period. Most of the increase occurred during the initial hour of exposure. The time required for equilibrium in blood to be reached was about 40 minutes. The concentration of TCE in the blood after a single four hour exposure was linearly dependent on the concentration of TCE inhaled by the animals exposed to $250 \mathrm{ppm}$ to $2000 \mathrm{ppm}$ TCE (fig 9). By contrast, the concentrations of TCE in blood of rats exposed to 4000 ppm TCE were lower than expected. The anaesthetic effects seemed to cause the suppression of the pulmonary uptake of TCE under $4000 \mathrm{ppm}$ exposure.

Figure 10 shows the relation between the avoidance response rate and the blood concentration, 


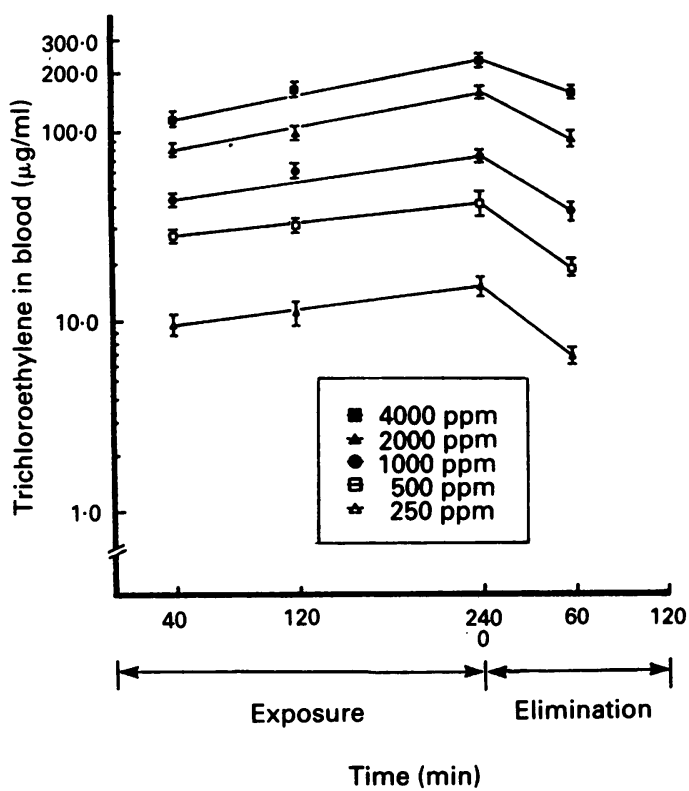

Figure 8 Concentration of TCE in blood of rats during and after a four hour inhalation exposure to TCE. Each point represents the geometrical mean for six rats.

estimated from the result of each exposure. Shock avoidance performance decrements occurred when the TCE concentrations were from $10-40 \mu \mathrm{g} / \mathrm{ml}$ of blood and central nervous system depression with anaesthetic performance disorders was produced by blood TCE concentrations of over $100 \mu \mathrm{g} / \mathrm{ml}$. The mean performance decrements when exposed to 1000 or $2000 \mathrm{ppm}$ TCE seemed to be a biphasic and non-linear function of the blood concentration, mainly because of the great variability of response of individual rats under both TCE exposures, as already mentioned.

\section{Discussion}

The data reported on the neurobehavioural effects of low exposure to TCE are conflicting. An experiment on humans ${ }^{9}$ in which volunteers were exposed for two four hour exposures of $110 \mathrm{ppm}$ TCE indicated significant alterations in performance on tests of tachistoscopic perception, immediate memory, and complex reaction time (both in response latency and regularity), whereas several subsequent attempts to obtain behavioural effects at concentrations of between 100 and $300 \mathrm{ppm}$ have failed. ${ }^{19-22}$

Exposure to TCE up to $200 \mathrm{ppm}$ is commonly thought to cause only subtle or no effects on the behaviour of experimental animals in acute exposures. ${ }^{10-12}$ When rats were trained to swim a $4 \mathrm{~m}$ alley with and without a $27 \mathrm{~g}$ load attached to their tails, an $800 \mathrm{ppm}$ concentration of TCE increased swimming time, but only with the load. Activity measured in other groups of rats showed that only exposure to $1600 \mathrm{ppm}$ TCE for five hours resulted in decrements in motor activity.$^{13}$ Our experiment, however, indicated that even a low exposure to TCE such as $250 \mathrm{ppm}$ for four hours resulted in shock avoidance performance decrements in rats (periods D and E, fig 1 ). This coincides well with a human exposure study with $\mathrm{TCE},{ }^{3}$ which showed that during exposure to $200 \mathrm{ppm}$ TCE for seven hours, $80 \%$ of the subjects reported fatigue and sleepiness and $50 \%$ reported that it took greater mental effort to perform the Romberg test.

Exposure to ranges of $250 \mathrm{ppm}$ to $2000 \mathrm{ppm}$ TCE for a period of four hours produced concentration related decreases in the avoidance response; nevertheless, the number of lever presses did not change and no excitatory behaviour was seen. By contrast, in our study on toluen $\mathrm{e}^{15}$ using the same behavioural and toxicological techniques, concentration related increases in lever presses and acceleration of the reaction time were found, which meant that toluene was, at concentrations such as 1000 or $2000 \mathrm{ppm}$, excitatory, although at other concentrations such as $4000 \mathrm{ppm}$, it was depressive. Both TCE and toluene have been abused because of the euphoric effects that some people experience on inhaling vapours - for example in

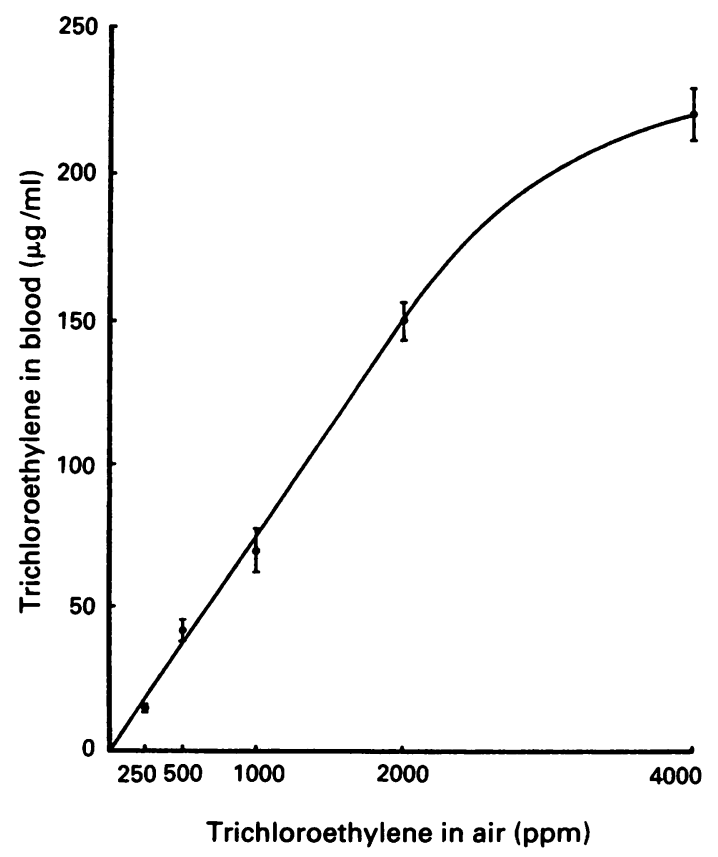

Figure 9 Blood TCE concentration in rats exposed to TCE just after a four hour inhalation. Each point represents the geometrical mean (2 SEM). 


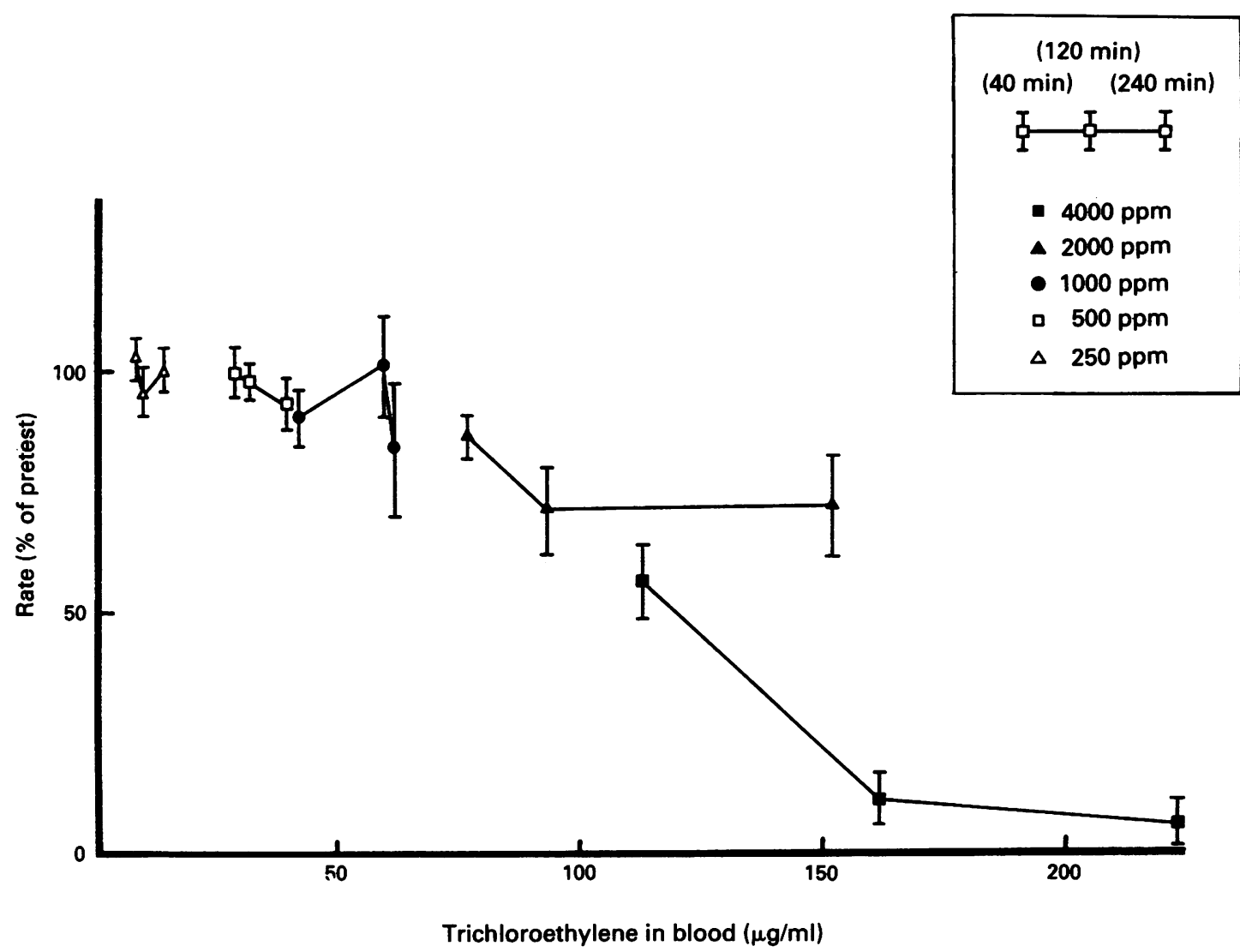

Figure 10 Relation between number of avoidances and blood TCE concentration. The mean (SEM) of lever pressing in eight rats at 20-40 minutes, 100-120 minutes, and 220-240 minutes after exposure are plotted against the mean TCE concentrations in the blood measured at the corresponding time.

one study about $4 \%$ of the workers were described as abusers. ${ }^{23}$ From our present experiment, however, it was clearly indicated that the acute effects of TCE on the central nervous system were quite different from those of toluene.

Special attention should be paid to the fact that the performance disorders continued and sometimes were more clear after the cessation of exposure than during exposure. The pronounced performance decrement as a result of exposure to $250 \mathrm{ppm}$ or $500 \mathrm{ppm}$ TCE continued for 80 to 140 minutes after the end of exposure (periods $F, G$, and $H$, figs 1 and 2 ). Why performance decrements after the termination of exposure to $250 \mathrm{ppm}$ and $500 \mathrm{ppm}$ TCE were significant might be because of the metabolite of TCE. ${ }^{24-26}$ As has been shown by many studies one third to one half of the retained amount of TCE is metabolised to trichloroethanol and excreted in the urine as urochloralic acid. Trichloroethanol seems to play an important part in the pharmacodynamic and toxic effect of TCE- for instance, it was reported that trichloroethanol was at least three, and probably five to six times more effective at the same dose as TCE as measured by the threshold current intensity of electrical skin stimulation and the electrical excitability of the motor cerebral cortex. ${ }^{27}$

There are only a few reports with data on blood concentrations of TCE during and after exposure. Astrand and Ovrum ${ }^{28}$ reported that during exposure to $540 \mathrm{mg} / \mathrm{m}^{3}(100 \mathrm{ppm})$ and $1080 \mathrm{mg} / \mathrm{m}^{3}$ $(200 \mathrm{ppm})$ of TCE, the arterial blood concentration increased linearly with the concentration in the alveolar air. The blood concentrations of TCE at rest after 30 minutes of exposure were $1.1 \mathrm{mg} / \mathrm{kg}$ and $2 \cdot 1 \mathrm{mg} / \mathrm{kg}$, respectively and during a 50 Watt exercise, $2.7 \mathrm{mg} / \mathrm{kg}$ and $6.0 \mathrm{mg} / \mathrm{kg}$ respectively. Sato et al ${ }^{29}$ reported that just after the termination of a four hour exposure to $100 \mathrm{ppm}$ TCE, blood concentration was $170 \mu \mathrm{g} / 100 \mathrm{ml}$ of blood. From these experiments on humans and our animal study, there seem not to be such large differences of 
concentration of TCE in blood between rats and humans. This is congruent with the fact that standardised metabolic capacities in rats and humans were considered to be similar to each other as judged by physiologically based pharmacokinetic data on trichloroethylene. ${ }^{30}$

The major purpose of this study was to investigate the critical concentration in blood associated with specific behavioural changes during and after exposure to TCE to understand the possible threshold and dose-response relation. According to our results, the effects on the central nervous system seem to be functions of both the exposure concentration and its duration, and are related to the increases in concentration of TCE in blood. It is estimated that depression of the central nervous system with slight performance decrements occurred when the blood concentration was 10 $\mu \mathrm{g} / \mathrm{ml}$ during exposure. Depression of the central nervous system with anaesthetic performance decrements was produced by a blood concentration of TCE of about $120 \mu \mathrm{g} / \mathrm{ml}$. Blood samples can be considered to be a reasonable index of the behavioural effects of TCE in experimental subjects, although the brain has a somewhat higher tissueblood partition coefficient for solvents than the liver and most other tissues except fat. ${ }^{31}$

In a physiological study with squid axons in vitro, ${ }^{32}$ TCE decreased axonal action potentials in proportion to the solvent concentration. The potentials returned to the central range after the solvent was removed from the medium. It is also reported that the acute depressive effects of TCE are due to effects on the excitable neural membranes. ${ }^{33}$ Behavioural effects found in the present study on exposure to TCE may be due to this physiological background.

Requests for reprints to: Reiko Kishi MD, PhD, Department of Public Health, Sapporo Medical College, Minami-1, Nishi-17, Chuo-Ku, Sapporo 060 Japan.

1 Rice ASC, Reynolds F. Comparison of trichloroethylene and euflurane as adjuncts to nitrous oxide and relaxant anaesthesia. Anaesthesia 1987;42:1320-3.

2 Nomiyama K, Nomiyama H. Dose-response relationship for trichloroethylene in man. Int Arch Occup Environ Health 1977;39:237-48.

3 Stewart RD, Dodd HC, Milwaukee AB, Gay HH, Erley DS, Mich H. Experimental human exposure to trichloroethylene. Arch Environ Health 1970;20:64-71.

4 Landrigan PJ, Kominsky KR, Ruth RL, Watanabe A. Common-source community and industrial exposure to trichloroethylene. Arch Environ Health 1987;42:327-32.

5 Mikiskova $\mathrm{H}$, Mikiska A. Some electrophysiological methods for studying the action of narcotic agents in animals, with special reference to industrial solvents: a review. $\mathrm{Br} F$ Ind Med 1968;25:81-105.

6 Konietzko HI, Elster P, Schomann P. Field studies in solvent factories. 5. Brain-electric correlations of trichloroethylene effects in telemetric electro-encephalography. Zentralblatt für Arbeitsmedizin Arbeitschutz und Prophylaxie 1976;26:60-3.

7 Stopps GI, McLaughlin M. Physiological testing of human subjects exposed to solvent vapors. Am Ind Hyg Assoc $\mathcal{F}$ 1967;28:43-50.

8 Vernon RJ, Ferguson RK. Effects of trichloroethylene on visual-motor performance. Arch Environ Health 1969;18:894-900.

9 Salvini M, Bisnaschi S, Riva M. Evaluation of the psycho- physiological functions in humans exposed to trichloroethylene. Br F Ind Med 1971;28:293-5.

10 Goldberg ME, Johnson HE, Pozzani UC, Syth HF. Behavioral response of rats during inhalation of trichloroethylene and carbon disulfide vapors. Acta Pharmacologica Toxicologica 1964;21:36-44.

11 Grandjean E. Trichloroethylene effects on animal behavior. Arch Environ Health 1960;1:106-8.

12 Grandjean E. The effects of short exposure to trichloroethylene on swimming performance and motor activity of rats. Am Ind Hyg Ass F 1963;24:376-9.

13 Ikeda T, Kishi R, Miyake H. In: Holmstedt R, Lauwerys $R$ Merder M, Roberfroid M, eds. Effects of long term exposure to trichloroethylene on learning behaviour in rats. Mechanisms of toxicity and hazard evaluation. Amsterdam: Elsevier, 1980: 91-4.

14 Kulig BM. The effects of chronic trichloroethylene exposure on neurobehavioural functioning in the rat. Neurotoxicology and Teratology 1987;9:171-8.

15 Kishi R, Harabuchi I, Ikeda T, Yokota $H$, Miyake $H$. Neurobehavioural effects and pharmacokinetics of toluene in rats and their relevance to man. $B r f$ Ind Med 1988;45:396-408.

16 Miyake H, Ikeda T, Maehara N, Harabuchi I, Kishi R, Yokota $\mathrm{H}$. Slow learning in rats due to long-term inhalation of toluene. Neurobehavioural Toxicology and Teratology 1983;5:541-8.

17 Ferster C, Skinner BF. Schedules of reinforcement. New York: Appleton Century Crafts, 1957.

18 Sato A, Nakajima T, Fujiwara Y. Determination of benzene and toluene in blood by means of a syringe-equilibration method using a small amount of blood. $B r \mathcal{F}$ Ind Med 1975;32:210-4.

19 Stewart RD, Hake CL, Lebrum AJ, et al. Effects of trichloroethylene on behavioral performance capabilities. In: Xintaras C, Johnson BL, deGroot Ido, eds. Behavioral toxicology, early detection of occupational hazards. Cincinnati: National Institute for Occupational Safety and Health, 1974:81-95.

20 Koniezko H, Elster I, Sayer H, Weichardt H. Zentral Nervose Schaden durch Tricholoroethylene. Staub-Reinhalt 1975; 35:240-1.

21 Ettema JH, Zielhuis RL. Effects of alcohol, carbon monoxide and trichloroethylene exposure on mental capacity. Int Arch Occup Environ Health 1975;35:117-32.

22 Gamberale F, Annwall G, Anshelm Olson B. Exposure to trichloroethylene. Psychological functions. Scand $\mathcal{f}$ Work Environ Health 1976;4:220-4.

23 Steuber K. Trichloroethylene industrial hazards. Arch Gewerbepath 1931;2:398-403.

24 Vesterberg O, Gorczak J, Krasts M. Exposure to trichloroethylene II. Metabolites in blood and urine. Scand $\mathcal{F}$ Work Environ Health 1976;4:212-9.

25 Ikeda $M$, Ohtujii $H$, Imamura $T$, Komoike $Y$. Urinary excretion of total trichloro-compounds, trichloroethanol, and trichloro acetic acid as a measure of exposure to trichloroethylene and tetrachloroethylene. $\mathrm{Br} \mathcal{F}$ Ind $\mathrm{Med}$ 1972;29:328-33.

26 Kimmerle G, Ebben A. Metabolism, excretion and toxicology of trichloroethylene after inhalation, 1. Experimental exposure in rats. Arch Toxicol 1973;30:115-26.

27 Mikiskova $\mathrm{H}$, and Mikiska A. Trichloroethanol in trichloroethylene poisoning. Br f Ind Med 1966;23:1 16-25.

28 Astrand I, Ovrum P. Exposure to trichloroethylene I. Uptake and distribution in man. Scand $\mathcal{f}$ Work Environ Health 1976;2:199-211.

29 Sato A, Nakajima T, Fujiwara Y, Murayama N. A pharmacokinetic model to study the excretion of trichloroethylene and its metabolites after an inhalation exposure. $\mathrm{Br} \mathcal{F}$ Ind Med 1977;34:56-63.

30 Koizumi A. Potential of physiologically based pharmaco-kinetics to amalgamate kinetic data of trichloroethylene and tetrachloroethylene obtained in rats and man. Br F Ind Med 1989;46:239-49.

31 Savolainen $H$, Pfaffli $P$, Tengen $M$, Vainio $H$. Tri-chloroethylene and l, l, l-trichloroethane: Effects on brain and liver after five days intermittent inhalation. Arch Toxicol 1977;38:229-37.

32 Shrivastav BB, Narashashi T, Kitz RJ, Roberts JD. Mode of action of trichloroethylene on squid axon membranes. Pharmacology and Experimental Therapeutics 1976;199: 179-88.

33 Haglid KG, Kjellstrand P, Rosengren L, Wronski A, Briving A. Effects of trichloroethylene inhalation on proteins of the gerbil brain. Arch Toxicol 1980;43:187-99.

Accepted 6 July 1992 